644 W. Enke und L. Heising: Zur Psychologie der „Aufmerksamkeitsspaltung“.

Damit ist auch an Hand des Formenversuches experimentell der Nachweis erbracht, daß der Grundtypus des konstitutionellen Verhaltens durch das Lebensalter nicht wesentlich verändert wird.

\title{
4. Zusammenfassung.
}

1. Auch bei farblosen Tests, bei Anwendung einfacher, geometrischer Formen, zeigt sich durchweg die größere Fähigkeit der Leptosomen und Athletiker zur Registrierung getrennter Reihen (Spaltungsfähigkeit) im Bewußtseinsablauf.

2. Das Lebensalter hatte keinen grundsätzlichen Einfluß auf die Versuchsergebnisse.

Daneben ergaben sich als neue Resultate:

3. Eine bei den Pyknikern nicht vorhandene Tendenz der Leptosomen, eigene Phantasieprodukte in einfache geometrische Formen zu projizieren.

4. Bei experimentell festgelegtem Zeitablauf des Versuches die geringere Fähigkeit der Leptosomen gegenüber den Pyknikern, sich einer von außen gegebenen Gesetzmäßigkeit unter- bzw. einzuordnen.

Die Verhaltungsweisen 3 und 4 lassen sich unschwer auf den schizothymen Autismus zurückführen.

\section{Literaturverzeichnis.}

Enke, W., Die Konstitutionstypen im Rorschachschen Experiment. Z. Neur. 108 (1927) - Experimentalpsychologische Studien zur Konstitutionsforschung. Z. Neur. 114, H. 5 (1928). - Heising, L., Über die Aufmerksamkeitsform der Körperbautypen. Inaug.-Diss. Marburg 1928. - van der Horst, Experimentellpsychologische Untersuchungen zu Kretschmers „Körperbau und Charakter“. Z. Neur. 93 (1924). — Kibler, M., Experimental-psychologischer Beitrag zur Typenforschung. Z. Neur. 98 (1925). - Kretschmer, E., Körperbau und Charakter. 5./6. Aufl. Berlin: Julius Springer 1926 - Medizinische Psychologie. 3. Aufl. Jeipzig: Thieme 1926 - Der heutige Stand der Konstitutionsforschung. Jkurse ärztl. Fortbildg 192\%, Maiheft. - Experimentelle Typenpsychologie. Z. Neur. 113, H. 4/5 (1928). - Liepmann, W., Psychomotorische Studien zur Konstitutionsforschung. Med. u. Film 3, Nr 16. - Munz, E., Die Reaktion des Pyknikers im Rorschachschen psychodiagnostischen Versuch. Z. Neur. 91 (1924). $S c h o l l, K$., Die teilinhaltliche Beachtung von Form und Farbe und ihre typologische Bedeutung. Z. Psychol. 101 (1927).

\section{Berichtigung.}

In Band 118, Heft 2, in der Arbeit Weiss muB es auf S. 173 unter Abb. 3 a heißen :

$$
\text { „Fall } 11^{\prime \prime} \text { statt „Fall 1". }
$$

